\title{
Note despre numele proprii în traducerile românești din secolul al XVIII-lea ale Vieții lui Petru (de Antonio Catiforo) ${ }^{\dagger}$
}

\author{
Cristian Ungureanu* \\ Facultatea de Litere, Universitatea „Alexandru Ioan Cuza”, Bd. Carol I 11, 700506 Iași, România
}

\begin{abstract}
Despre articol
Istoric:

Primit 21 noiembrie 2016

Acceptat 31 decembrie 2016

Publicat 13 ianuarie 2017

Cuvinte-cheie:

traducere

onomastică

literatură veche

scriere laică

Rezumat

Vita di Pietro este o lucrare alcătuită de grecul Antonio Catiforo în limba italiană, publicată la Veneția, în 1736; o versiune a sa în limba greacă a fost publicată tot la Veneția, un an mai tîrziu, de către Alexandros Kankellarios. Lucrarea conține șase cărți și sintetizează informațiile oferite de surse referitoare la epoca și personalitatea țarului rus. În română, ea a cunoscut mai multe traduceri la jumătatea şi în a doua perioadă a secolului al XVIII-lea, în toate cele trei provincii românești. Numărul mare de copii arată interesul de care s-a bucurat această lucrare în epocă.

Articolul de față prezintă cîteva particularități ale transferului numelor proprii din limba-sursă în limba-țintă. Am analizat patru tipuri de nume proprii: horonimul Moscovia și etnonimul aferent, horonime occidentale, antroponime rusești, antroponime de alte origini, urmărind felul în care traducătorii se raportează la sursă și diferențele dintre versiuni din acest punct de vedere.
\end{abstract}

\section{Introducere}

În 1736, în „Novelle della repubblica letteraria” se anunța publicarea lucrării Vita di Pietro il Grande Imperador della Russia estratta da varie memorie pubblicate in Francia e in Olanda, per opera dell'abate greco Antonio Catiforo, relatarea, în șase cărți, a vieții țarului rus, precedată de un scurt rezumat al istoriei ruse anterioare venirii acestuia la putere. Autorul este Antonio Catiforo, un grec din insula Zante care a studiat mai întîi la Colegiul grecesc „Sf. Atanasie” de la Roma, apoi s-a transferat la Veneția, unde a fost consacrat diacon în 1710, păstrînd, se pare, mereu o poziție doctrinară „de graniță” (Falcetta, 2010). Scrie Vita di Pietro în anii conflictului ruso-otoman. Prin publicarea cărții, Antonio Catiforo nu intenționa neapărat să propună suveranilor europeni un model de guvernare luminată, ci mai ales să obțină intervenția guvernării rusești în procesul de emancipare politică a popoarelor din Balcani. Prima ediție (1736) este anonimă, textul de închinare adresat ducelui Michiel Morosini este semnat de tipograful Francesco Pitteri; abia din 1739 lucrarea poartă semnătura autorului. Biografia lui Petru cel Mare a avut, mai ales în versiunea sa în limba greacă (Kankellarios, 1737), o circulaţie amplă în Europa orientală, fiind tradusă în română, croată și rusă (Falcetta, 2010, nota 67).

În Țările Române, lucrarea lui Catiforo cunoaște trei traduceri paralele, toate păstrate în copii manuscrise. Prima dintre acestea a fost efectuată în Țara Românească de către Mihai Fărcășanu, care făcea parte dintr-o veche și importantă familie boierească. Traducerea lui Fărcăşanu, realizată, aşa cum spune unul dintre copiști, în 1749, a fost păstrată în trei copii muntenești din acelaşi secol: ms. 204 BAR (1749), ms. 2353 BAR (1755), ms. 2668 BAR (1767). Titlul traducerii este: Viața Marelui Petru, aftocrator a toată Rosia, părintele patriei, adunată din multe pomeniri în Franța și în Olanda, ce s-au dat în doao tomuri, iară mai pre urmă s-au tălmăcit den limba italienească în limba grecească cu toată nevoința de chir Alexandru Canțelariu, iară după cea grecească s-au tălmăcit acum la înțelegerea rumânească de dumnealui Matei Fărcășanu, biv vel șatrar, la anii de la Hristos 1749. Titlul, reprodus după una dintre copii (ms. 2353), indică

\footnotetext{
${ }^{\dagger}$ Articol realizat în cadrul proiectului CNCS PN-II-RU-TE-20144-1108, Practici de traducere a numelor proprii în scrisul românesc premodern (1780-1830).

*Adresă de corespondență: cristiungureanu@libero.it.
} 
relația dintre traducerea românească și sursele sale, arătînd că textul românesc urmează sursa grecească, nu originalul italian; prefața traducătorului indică același lucru, subliniind și ideea istoriei ca model pentru prezent și a lecturii ca activitate utilă spiritului uman. Analiza lingvistică a unui fragment, întreprinsă recent (Dima \& Dima, 2013, p. 73), a arătat că afirmațiile din titlu și din prefață sînt reale, originalul find, într-adevăr, versiunea grecească a lucrării, la care traducătorul român se raportează selectiv, omițînd unele dintre intervențiile autorului acesteia.

De la jumătatea secolului al XVIII-lea datează și traducerea moldovenească, păstrată în patru copii: ms. 49 BAR (1756), ms. 122 BAR (1756), ms. 2581 BAR (1799), ms. nr. 1 din fondul românesc, la Biblioteca „Saltîkov-Șcendrin” Sankt-Petersburg (1799) (Dima \& Dima, 2013, p. 113). De data aceasta, nici sursa, nici traducătorul nu sînt indicate. Analiza textuală a arătat că și la baza acestei traduceri a stat originalul grecesc (fonetisme grecești, împrumuturi ad hoc, locuri în care versiunea greacă diferă de cea italiană, iar traducerea românească o urmează pe cea greacă). Pe autorul versiunii moldovenești, Ursu (2002, p. 55) l-a identificat în persoana lui Cozma Vlahul, cleric de la Mitropolia din Iași, autorul mai multor traduceri din greacă.

Cea de-a treia versiune românească, păstrată în două copii din a doua jumătate a secolului al XVIIIlea: ms. 3161 BAR (1788, p. 1-186: Istoria rușilor și viața Marelui Petru, monarbul rușilor, și vitejiele lor. Cartea politiei rusești și vitejiile rușilor, a monarhului Petru și altor împărați și stăpînitori. Istoriile acestea sînt scoase de pe limba muscăcească pe limba rumânească de domnia lui, chirio, chir Rodion Popovici, dascalul orașului cetății Coronii), ms. 2476 BAR (1783), a fost realizată la Brașov de un traducător neidentificat. Paginile de titlu ale copiilor indică drept intermediar o versiune rusească; comparația textuală a arătat, însă, că și această versiune a fost tradusă după cea grecească (aşa cum indică împrumuturile contextuale) (Dima \& Dima, 2013, p. 152).

În stabilirea sursei directe a traducerii au fost implicate sporadic și numele proprii. În cele ce urmează, voi analiza comparativ modalitatea în care au fost transpuse cîteva nume proprii în cele trei traduceri paralele (am avut în vedere, dintre numeroasele copii: ms. 2353, Muntenia; ms. 49, Moldova; ms. 3161, Transilvania - Braşov). De asemenea, studiul comparativ al celor trei traduceri paralele cu aceeași sursă, dincolo de datele referitoare la dialectologia istorică și istoria limbii române, poate aduce informații interesante referitoare la atitudinea față de traducere sau la ponderea tradiției culturale în procesul de transfer al numelor proprii în limba țintă.

\section{Despre tratamentul numelor proprii}

\subsection{Probleme generale}

Considerațiile de mai jos valorifică date obținute în cadrul proiectului de cercetare „Practici de traducere a numelor proprii în scrisul românesc premodern (1780-1830)”, desfășurat la Universitatea „Alexandru Ioan Cuza” din Iași. Întrucît prima etapă, stabilirea bibliografiei și excerptarea corpusului de nume proprii din texte reprezentative ale perioadei, este încă în desfășurare, analiza noastră se bazează doar pe un copus parțial al numelor proprii din traducerile românești ale biografiei lui Petru cel Mare; studiul lor integral poate evidenția și alte modalități de transpunere. De altfel, această traducere oferă un fertil teren de cercetare avînd în vedere că este vorba despre transpuneri paralele (aşa cum a arătat comparația versiunilor), din zone diferite ale spațiului dacoromân; toate traducerile valorifică versiunea în limba greacă (în ciuda notaţiei de pe pagina de titlu a versiunii transilvănene-Istoriile acestea sînt scoase de pe limba muscăcească pe limba rumânească-, comparația textuală a arătat că și în cazul acesta traducerea s-a făcut tot după versiunea grecească, concluzie susținută, după cum vom vedea, și de analiza numelor proprii).

În ceea ce privește transferul numelor proprii dintr-o limbă în alta, în actul traducerii, au fost identificate, în literatura de specialitate, mai multe procedee, cele mai frecvente, pentru numele proprii opace ${ }^{1}$,

\footnotetext{
${ }^{1}$ Numele proprii „opace” („pure”, non-descriptive”, „prototipice”) sînt forme nominale monolexicale (cu observația că nu toate numele monolexicale sînt opace) specializate ca nume proprii, ușor recognoscibile ca atare, lipsite de conținut lexical; spre deosebire de acestea, numele proprii descriptive nu sînt total desemantizate, apelativul de la baza lor fiind recognoscibil (vezi,
} 
fiind transliterația, transcrierea, asimilarea fonetică / grafică, în diverse grade de realizare (Ballard, 2011, p. 23-67). Este evident că fiecare epocă sau cultură are modalități preferate de transfer al numelor proprii. Lucrurile se complică atunci cînd în procesul de transfer intervin factori ca lipsa de normare (cu atît mai evidentă, pe plan românesc, cu cît ne îndepărtăm de epoca prezentă) sau probleme specifice anumitor culturi. Pentru transpunerea numelor proprii rusești, de exemplu, Sakhno (2006), referindu-se strict la epoca contemporană și la un corpus preluat de pe internet, remarcă fluctuațiile în transcrierea și chiar în transliterarea acestora în limba franceză, arătînd că, pe de o parte, transcrierea nu redă întotdeauna pronunția rusească (mai ales atunci cînd aceasta este necunoscută utilizatorului), și, pe de altă parte, nici transliterarea nu e mereu exactă (dincolo de posibilele probleme de nivel semantic).

În ceea ce privește traducerile românești ale biografiei petrine, analiza transpunerii numelor proprii trebuie să țină seama de interferența a trei alfabete diferite: alfabetul latin (versiunea originală, în limba italiană), alfabetul grecesc (versiunea intermediară) și cel chirilic (sistemul grafic al limbii române în epocă). De asemenea, transpunerile numelor proprii mărturisesc relații interlingvistice complexe, date de tema lucrării, pe de o parte, și de relațiile de tip original-traducere, pe de altă parte. Astfel, în unele cazuri, traseul lingvistic pe care îl urmează numele propriu este: rusă (limba de origine a numelui propriu, întrucît este limba personajelor şi a contextului lucrării) $\rightarrow$ italiană $\rightarrow$ greacă $\rightarrow$ română (e.g. Иван Васильевич $\rightarrow$

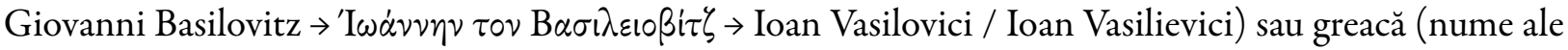

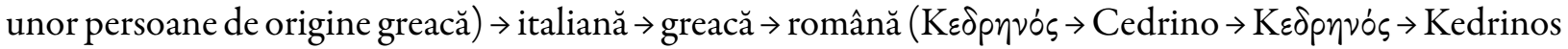
/ Kedrin); etape ale acestui traseu pot fi eludate, pe baza cunoștințelor extratextuale ale traducătorului sau copistului (rusă $\rightarrow$ română, în cazul unor nume proprii de origine rusă, preluate direct din limba de origine de un traducător familiarizat cu această limbă sau măcar cu sonoritățile sale, cum este cazul numelui țarului Ioan Vasilievici, invocat mai sus, unde forma din română nu este justificată de cea a originalului grecesc, ci de familiarizarea traducătorului sau a copistului cu numele proprii rusești).

\subsection{Aplicații}

Vom analiza, în cele ce urmează, modalitățile de transpunere a unor nume proprii opace în textele avute în vedere, urmărind cărei culturi de referință îi este tributară traducerea românească, ce modalități de transfer al numelor proprii sînt utilizate, preferința pentru anumite procedee ale variantelor românești sau orientarea lor spre anumite modele culturale. Am ales să ne oprim asupra a patru grupuri de nume proprii: (oico-)horonimul Moscova și etnonimele corespunzătoare; horonime occidentale; antroponime rusești; antroponime occidentale.

\subsubsection{Moscova, muscal, moscovit}

Numele propriu Moscovia denumește, în originalul italian, regiunea, parte a Marelui Cnezat Rus în trecut (Marele Principat al Moscovei pînă la 1547), în care este situată, în contemporaneitatea textului, capitala Imperiului Rus: „Moscovia è propriamente una sola delle molte Provincie, che compongono l'Imperio Russiano" (Catiforo, 1736, p. 19). Versiunea grecească preia întocmai acest horonim, prin transliterare: Mooxoßia (Kankellarios, 1737, p. 3). Cele trei versiuni românești procedează diferit: dacă ms. 2353 și ms. 3161 se folosesc de transliterare („Moscovia este una dintre acele eparhii”, ms. 2353, 140 ; „Moscoviia iaste una dintre multe Eparhii întru împărățiia rusească”, ms. 3161, $2^{\text {r }}$ ), versiunea din Moldova echivalează printr-o sintagmă alcătuită din nume comun și adjectiv derivat din horonim, sintagmă de model slavon, folosită în mod tradițional în scrisul românesc vechi pentru a denumi numele de țări: Țara Moschicească (ms. 49, $2^{\text {r }}$. În alt loc, pentru a desemna același referent (regiunea Moscova), deși cele două surse folosesc aceleași horonime, traducerea din Transilvania utilizează o altă formă, de asemenea tradițională în scrisul românesc vechi: Mosc („Aerul Moscului iaste atîta de rece”; ,zic aşa că să fie Moscul în Olandiia”, ms. 3161, $\left.2^{\mathrm{v}}\right)$.

pentru tipologia numelor proprii, Gînsac, 2013, p. 51-57). În traducere, cu cît un text se îndepărtează mai mult de sursa sa primară, cu atît semnificația sa se „opacizează”; este ceea ce se întîmplă cu numele biblice, antroponime sau toponime, care, în traducerile în limbile moderne, de pildă, își pierd caracterul descriptiv pe care îl aveau în ebraică. Vezi, pentru acest aspect și pentru problematica numelui propriu biblic, în general, Gafton (2005, p. 167-172). 
Faptul că forma Moscovia nu este obișnuită pentru spațiul românesc determină înlocuirea sa prin alte forme, uzuale, pentru care traducătorii fac apel la propriul orizont de cunoaștere; astfel, în ms. 2353 se preferă Moscova („supt numele Moscovei”, 140r), iar în ms. 3161, Moscvia („supt numele Moscviei”, $2^{\mathrm{r}}$ ).

Etimologia numelui cetății este explicată astfel în originalul italian: „quella appunto, che vien bagnata dal fiume Mosca, da cui prende il suo nome la Città, Capitale di quella Provincia, e di totta la Monarchia” (Catiforo, 1736, p. 19), indicînd omonimia dintre hidronim și oico-horonim (spre deosebire de această situație, în limba italiană de astăzi denumirea capitalei Rusiei este Mosca, în timp ce hidronimul are forma

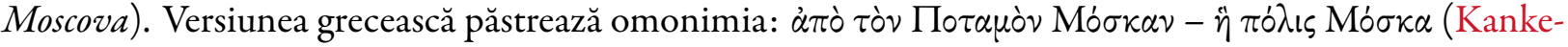
llarios, 1737, p. 3), ca și cele românești: „apa Moscăi” - „cetatea Mosca” (ms. 2353, 140 ), ,apa Moscvei”

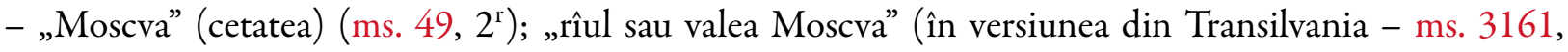
unde numele cetății nu este echivalat). Observăm formele oscilante în transferul acestui oiconim: dacă textul din Muntenia transferă numele propriu, din nou, prin transliterare, traducătorul moldovean și cel transilvănean fac apel, ca și în cazul horonimului, la forme din propriul orizont de cunoaștere.

Oscilații înregistrează traducerile românești și în privința etnonimului provenit din numele cetăţii Moscova. Astfel, locuitorii regiunii sînt denumiți, în originalul italian, Moscoviti, iar în cel grecesc, Mo «xo-

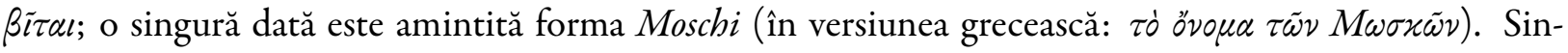
gurul text românesc care echivalează ambele denumiri este cel din Transilvania: „numele moscon, sau al moscalilor" (ms. 3161, 3v), în timp ce celelalte două prezintă, în acest loc, un singur nume propriu: „numele muscalilor” (ms. 2353, 141 v), „numele moscovilor” (ms. 49, 3v). Semnalăm transliterarea, în versiunea transilvăneană, a etnonimului cu tot cu terminația grecească de genitiv plural (moscon). Pe lîngă etnonimul muscal (moscal), derivat de la Mosc și aflat în uz în spațiul românesc al epocii, textele prezintă și alți echivalenți: moscovi (derivat de la Moscova, $\mathrm{ms} .49,3^{\mathrm{v}}$ ), moscovitii (preluare a etnonimului din original, fără alternanța fonetică $t-t$, , în ms. $3161,3^{\mathrm{v}}$, dar moscoviți, pe aceeași pagină). În alte locuri, opțiunile traducătorilor români sînt convergente, făcînd apel la etnonimul obișnuit în țările române: $i$ Moscoviti

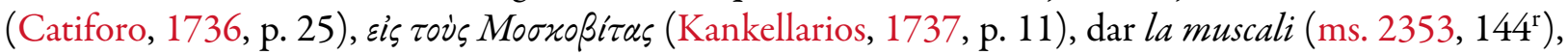
intru moscali (ms. 49, $5^{\mathrm{r}}$ ), muscalilor (ms. 3161, $6^{\mathrm{r}}$ ).

Sintetizarea observațiilor despre echivalarea acestui etnonim, aşa cum apare în tabelul următor, indică o surprinzătoare consecvență în textul muntenesc și în cel moldovenesc, în timp ce versiunea transilvăneană se caracterizează prin oscilația între formele deja consacrate și inovații contextuale:

\begin{tabular}{|c|c|c|c|c|}
\hline italiană & greacă & ms. 2353 & ms. 49 & ms. 3161 \\
\hline il nome di Moschi o & $\tau \grave{~}{ }^{\prime} \nu \sigma \mu \alpha \tau \tilde{\omega} \nu \mathrm{M} \omega \sigma \kappa \tilde{\omega} \nu$, & numele & numele & numele moscon \\
\hline Moscoviti (p. 22) & 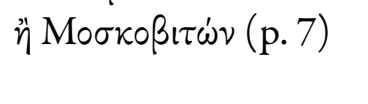 & $\begin{array}{l}\text { muscalilor } \\
\left(141^{\mathrm{v}}\right)\end{array}$ & $\begin{array}{l}\text { moscovilor } \\
\left(3^{v}\right)\end{array}$ & al muscalilor $\left(3^{v}\right.$ \\
\hline I Moscoviti (p. 22) & 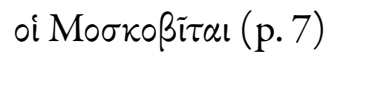 & $\begin{array}{l}\text { muscalii } \\
\left(142^{r}\right)\end{array}$ & $\begin{array}{l}\text { moscovii } \\
\left(3^{v}\right)\end{array}$ & $\operatorname{moscovitii}\left(3^{\mathrm{v}}\right)$ \\
\hline Moscoviti (p. 22) & 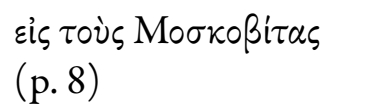 & $\begin{array}{l}\text { muscali } \\
\left(142^{r}\right)\end{array}$ & $\operatorname{moscovi}\left(3^{v}\right)$ & Moscoviți $\left(3^{\mathrm{v}}\right)$ \\
\hline Moscoviti (p. 22) & 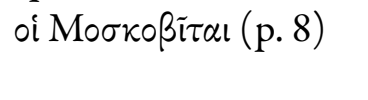 & $\begin{array}{l}\text { muscalii } \\
\left(142^{\mathrm{r}}\right)\end{array}$ & $\begin{array}{l}\text { (secvență } \\
\text { netradusă) }\end{array}$ & $\operatorname{Moscoviții~}\left(3^{v}\right)$ \\
\hline
\end{tabular}

Interesant este și etnonimul rosilor (ms. $49,3^{\mathrm{v}}$; în celelalte două traduceri românești: ruşilor). Originalul italian și versiunea grecească propun, și în acest loc, două forme ale etnonimului: „Rossi o Russi” (Catiforo,

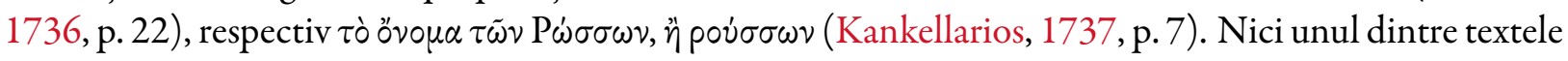
românești nu indică două forme în acest caz. Dacă traducerea muntenească și cea transilvăneană reproduc prin etnonimul uzual, textul moldovenesc se păstrează mai aproape de original, prin evitarea alternanței fonetice $s-s$.

Dacă textele originale mărturisesc o delimitare clară a horonimelor Rusia și Moscovia (primul se referă la Imperiul Rus, al doilea, la regiunea Moscovei), traducerea muntenească nu păstrează această diferențiere semantică, așa cum indică echivalarea secvenței „gli Annali della Russia” (Catiforo, 1736, p. 22), respectiv 


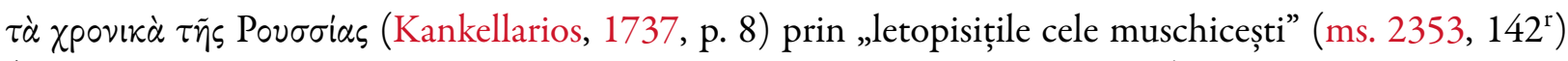
(„letopisițile Rosiii”, ms. 49, $3^{\mathrm{v}}$, respectiv „hronografurile rusești”, ms. 3161, $3^{\mathrm{v}}$ ).

\subsubsection{Horonime occidentale}

Se întîlnesc în text numele unor state sau regiuni din Europa occidentală, transpuse astfel:

\begin{tabular}{|c|c|c|c|c|}
\hline $\begin{array}{l}\text { italiană (Catiforo, 1736, } \\
\text { p. 20) }\end{array}$ & $\begin{array}{l}\text { greacă (Kankellarios, } \\
1737, \text { p. 4) }\end{array}$ & $\begin{array}{l}\text { ms. } 2353, \\
140^{\mathrm{v}}\end{array}$ & ms. $49,2^{r}$ & ms. $3161,2^{v}$ \\
\hline che tutta la Francia & $\dot{\alpha} \pi \grave{\partial} \tau \dot{\alpha} \varsigma \Gamma \alpha \lambda \lambda i \alpha \varsigma$ & Franța & Galia & Galia \\
\hline la Spagna & 'I $\sigma \pi \alpha \nu i \alpha \nu$ & Ișpania & Ispania & Ișpania \\
\hline l'Italia & 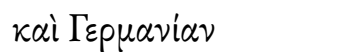 & Ghermania & Ghermania & Ghermania \\
\hline Olanda & $\varepsilon i \varsigma \tau \dot{\eta} \nu \mathrm{O} O \lambda \alpha \nu \delta \dot{i}^{\prime} \alpha \nu$ & Olanda & Olanda & Olandiia \\
\hline la Sicilia & 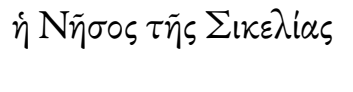 & $\begin{array}{l}\text { ostrovul } \\
\text { Sichilei }\end{array}$ & $\begin{array}{l}\text { ostrovul } \\
\text { Sicheliei }\end{array}$ & $\begin{array}{l}\text { ostrovul } \\
\text { Secheliei }\end{array}$ \\
\hline
\end{tabular}

După cum se vede, modelul dominant este cel grecesc. În unele cazuri, însă, se folosesc formele de influență occidentală (Franța, Olanda). Este greu de presupus că traducătorii aveau la dispoziție și sursa italiană; mai plauzibilă este ipoteza că formele de acest tip făceau parte din experiența lor culturală.

Pentru desemnarea orașului Constantinopole se folosește denumirea tradițională Țarigrad (deși ambele surse au, firește, Constantinopole). O singură dată se întîlnește, în versiunea din Transilvania, forma Constandinopol.

\subsubsection{Antroponime rusești}

În prezentarea dinastiei Rurik, primii conducători ai Moscovei, este menționată soția lui Igor cel Bătrîn, Olga (903-969), nume propriu care în originalul italian are forma Olla (Catiforo, 1736, p. 23), iar în

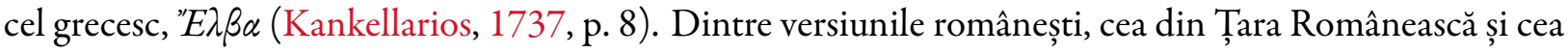
din Transilvania transcriu numele din sursa grecească (Elva), în timp ce textul moldovenesc folosește cu consecvență numele propriu rusesc Olga, cu varianta Olva. Mai degrabă decît utilizarea unei eventuale surse rusești, este de presupus aici că traducătorul apelează, în echivalarea numelui propriu respectiv, la un echivalent uzual pentru el (legăturile Moldovei cu Rusia sînt mai strînse decît ale celorlalte provincii românești, ceea ce ar explica faptul că antroponimul rusesc nu se întîlnește și în celelalte două). De remarcat este că într-un loc din versiunea transilvăneană transcrierea antroponimului se face cu tot cu terminația de acuzativ din limba sursă, după care el este integrat în sistemul feminin al antroponimelor românești, adăugîndu-i-se terminația - $a$ : gr. $\tau \dot{\eta} \nu{ }^{\prime \prime} E \lambda \beta \alpha \nu$ (Kankellarios, 1737, p. 8) - „, ,-au luat muiare pre Elvana" (ms. 3161, 4 ${ }^{\mathrm{r}}$ ). Astfel de observații vin să infirme ideea că traducerea acestui text urmărește o sursă rusească (aşa cum susține pagina de titlu), arătînd că sursa lui este, ca și în cazul celorlalte două versiuni românești, grecească.

Numele Ivan Vasilievici (Ivan al IV-lea, Ivan cel Groaznic) este transferat în italiană sub forma Giovanni Basilovitz (Catiforo, 1736, p. 25). La baza transferului prenumelui stă procedeul numit de Michel Ballard ,asimilare fonetică” (Ballard, 2011, p. 42-46), adică utilizarea, pentru un nume propriu din limbasursă, a unui nume propriu deja existent în sistemul limbii-țintă, adaptat la sistemul fonetic al acesteia. În ceea ce privește patronimul, textul italian preia forma sa regională, cu $o$, în timp ce forma cu $e$ pare a fi de origine rusă. Interesant este, de asemenea, că, deși limba italiană conţine, în sistemul său consonantic, semioclusiva $\check{c}$, care se regăsește în numele propriu, în textul italian aceasta este înlocuită prin $t(=$ tz): Giovanni Basilovitz (Catiforo, 1736, p. 25); faptul acesta se poate explica prin originea grecească a

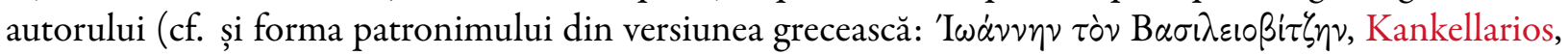
1737, p. 12). În limba română, în toate cele trei versiuni, prenumele este transferat prin acelaşi procedeu al asimilării, sub forma $I_{o a n^{2}}$, în timp ce patronimul, pe de o parte, are africata caracteristică din limba rusă

\footnotetext{
${ }^{2}$ Utilizarea acestei modalități de transfer pentru numele foarte cunoscute este caracteristică epocii; astfel, de exemplu, în traducerea românească a Istoriei Americăi de Constant d'Orville (traducere a arhimandritului Gherasim, păstrată într-o copie de
} 
Cristian Ungureanu

(Vasilovici, ms. 2353, 144 ${ }^{\mathrm{r}}$; Vasiliievici, ms. 49, $5^{\mathrm{r}}$; Vasilievici, ms. 3161, ${ }^{\mathrm{r}}$ ), pe de alta, prezintă, de la un text la altul, oscilația vocalei $o$ / ie. Și aici, așadar, numele propriu nu este preluat ca atare din sursa traducerii, ci în echivalarea sa traducătorii au în vedere cunoștințele lor de limbă și cultură rusă preexistente actului traducerii.

\subsubsection{Antroponime de alte origini}

Este o caracteristică a limbii italiene faptul că transferul numelor proprii străine se face prin adaptarea lor fonetică (vezi, și astăzi, Monaco pentru München, Colonia pentru Köln etc.). Astfel, numele lui (Philipp) Clüver, istoric și geograf german (1580-1622), este adaptat fonetic prin înlocuirea vocalei închise anterioare rotunjite $[y]$ (notată $\ddot{u}$ ), pe care sistemul vocalic italian nu o conține, cu $u$, iar terminația -io provine din -ius, terminația formei latinizate a numelui (Philippus Cluverius) ${ }^{3}$. În limba greacă, terminația suferă transformarea specifică în -ios. Transferul numelui în limba română se face prin adaptarea terminației, după model slavon: „Dar Cluverie [...] arată această întoarcere a muscalilor ca o minune” (ms. 2353, $143^{\mathrm{v}}$ ), „Iară Cluverie [...] ca o mare minune o arată pre întoarcire aceasta” (ms. 49, 4v), „Ci Cluverie [...] pune ca o minune această întoarcere" (ms. $\left.3161,5^{\mathrm{v}}\right)$.

Numele cronicarului bizantin (Gheorghios) Kedrenos, adaptat în italiană prin înlocuirea consoanei

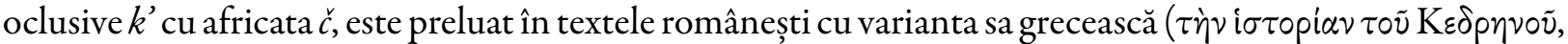
Kankellarios, 1737, p. 11), în care vocala $\eta$ are pronunția neogrecească: Kedrin (ms. 49, 4v ; ms. 3161, $5^{\mathrm{v}}$ ), Kedrinos (transliterare, ms. 2353, 143v).

\section{Concluzii}

Examinarea unui eșantion din numele proprii din cele trei versiuni românești ale lucrării Vita di Pietro a lui Antonio Catiforo pune în evidență cîteva dintre modalitățile de transfer al numelor proprii în limba română, în secolul al XVIII-lea. Procedeele de transfer sînt diferite în interiorul aceluiași text, în funcție de gradul de cunoaștere pe care îl are traducătorul în raport cu realitatea desemnată de numele propriu și, de asemenea, de existența sau nonexistența unei tradiții a respectivului nume propriu în scrisul românesc de pînă atunci. Astfel, unele nume proprii sînt transferate prin transliterare, în timp ce pentru altele traducătorul se folosește de forme ale numelui deja cunoscute de el. Uneori, numele proprii sau etnonimele sînt transcrise cu tot cu terminația cazuală din limba de origine (e.g. moscon, Elvana, în versiunea din Transilvania păstrată în ms. 3161). În ceea ce privește etnonimele, traducătorii le aleg pe cele care circulau deja în spațiul românesc; în acest sens, unele versiuni se caracterizează printr-un grad mai mare de consecvență, în timp ce altele oscilează între mai mulți echivalenți.

Corpusul studiat aici este o mică parte din cel excerptat din traduceri românești de texte istorice și geografice din secolul al XVIII-lea, în cadrul proiectului Practici de traducere a numelor proprii în scrisul românesc premodern (1780-1830). Proiectul a pornit de la constatarea particulară a inconsecvenței cu care sînt manipulate numele proprii inclusiv în traducerile contemporane, în paralel cu aceea, mai generală, a lipsei de standardizare a numelor proprii din limba actuală, și și-a propus să vadă care era situația acestei categorii în perioada premodernă a limbii literare și dacă se pot găsi, aici sau, prin comparație, în epocile următoare, bazele unei standardizări. În acest sens, numele studiate în articolul de față fac să se întrevadă o tendință a epocii, aceea de a adapta numele proprii mai puțin obișnuite la sistemul onomastic românesc, spre deosebire de tendința din limba actuală.

la 1800), numele regelui Juan I al Portugaliei, prezent ca Jean I în sursa franceză, este transpus prin Ioan întîiu ( $\left.3^{\mathrm{v}}\right)$. Modelul, adesea, nu este cel al sursei, ci cel al limbii grecești, foarte cunoscută traducătorilor epocii, ceea ce face ca, în aceeași lucrare, toponimul Neaples să apară ca Neapolis, antroponimul Héraclide ca Iraclie etc. Modelul limbii grecești este vizibil și în numele proprii transpuse în română prin transliterare, în cazuri ca Cfito (fr. Quito), Hili (fr. Chili) etc. (dar țărmurile Ghinei, cf. fr. les côtes de Guinée, sau Séres, cf. fr. Cérès; Asorile, cf. fr. les Açores).

${ }^{3}$ Prin numele latinizat se poate explica, de altfel, și vocala posterioară. 


\section{Bibliografie}

\section{A. Surse}

Catiforo, A. (1736). Vita di Pietro il Grande, imperador della Rusia; estratta da varie Memorie pubblicate in Francia e in Olanda, Veneția.

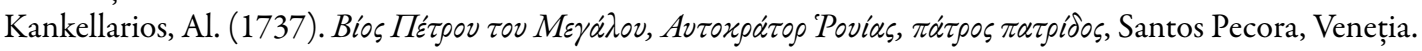

Ms. 2353 = Viiața Marelui Petru, aftocrator a toată Rosiia, părinte patriei, adunată din multe pomeniri în Franța și in Olanda, ce s-au dat in doao tomuri, iară mai pe urmă s-au tălmăcit den limba italienească in limba grecească cu toată nevoința de chir Alexandru Canțelariu, iară după cea grecească s-au tălmăcit acum la ințtelegerea rumânească de Dumnealui Matei Fărcăsan, biv vel șatrar, la anii de la Hristos 1749. Ms. rom. 2353 BAR.

Ms. 3161 = Istoria rușilor și viața Marelui Petru, monarbul rușilor, și vitejiele lor. Cartea politiei rusești și vitejiile rusilor, a monarbului Petru și altor împărați și stăpinitori. Istoriile acestea sînt scoase de pe limba muscăcească pe limba rumânească de Domniia lui, Chirio Chir Rodion Popovici, dascalul orașului cetății Coronii, și după izvodul acela s-au scris a doa oară de smeritul robul lui Dumnezeu Zanfir Marco capitan. Ms. rom. 3161 BAR.

Ms. 49 = Viața Marelui Petru, Samoderjeț a toată Rosiia. Ms. rom. 49 BAR.

\section{B. Lucrări de referință}

Ballard, M. (2011). Numele proprii în traducere, traducere integrală din limba franceză. Coordonare traducere, Cuvînt înainte la ediția în limba română și note de traducere de Georgiana Lungu-Badea, Editura Universității de Vest, Timișoara.

Dima, E. \& Dima, G.E. (2013). Vita di Pietro de Antonio Catiforo și versiunile românești din secolul al XVII-lea, Editura Universității „Alexandru Ioan Cuza”, Iași.

Falcetta, A. (2010). Diaspora ortodossa e rinnovamento culturale: il caso dell'abate greco-veneto Antonio Catiforo (1685-1763), în „Cromohs”, 15, p. 1-24, [online].

Gafton, Al. (2005). Numele in Biblie, în AUI, Secțiunea IIIe. Lingvistică, Tomul LI, 2005, p. 165-179.

Gînsac, A.-M. (2013). Teonimie românească. Concept, metodă, probleme, Editura Universității „Alexandru Ioan Cuza”, Iași.

Sakhno, S. (2006). Noms propres en russe: problemes de traduction, în „Meta: journal des traducteurs”, vol. 51, nr. 4, p. 706-718, Crossref.

Ursu, N.A. (2002). Un traducător puțin cunoscut: ieromonabul Cozma Vlabul de la mitropolia din Iași, în Contribuții la istoria culturii românești. Studii și note fllologice, Editura Cronica, Iași, p. 44-75. 